\title{
Phát triển chương trình đào tạo, bồi dưỡng giáo viên đáp ứng yêu cầu đổi mới giáo dục phổ thông Việt Nam
}

\author{
Hoàng Thanh Tú ${ }^{1, *}$, Ninh Thị Hạnh ${ }^{2}$ \\ ${ }^{I}$ Truò̀ng Đại học Giáo dục, ĐHQG Hà Nội, 144 Xuân Thủy, Cầu Giá́y, Hà Nội, Việt Nam \\ ${ }^{2}$ Khoa Lịch sử, Truò̀ng Đại học Su phạm Hà Nội 2, \\ Số 32 Nguyễn Văn Linh, Xuân Hoà, Phúc Yên, Vĩnh Phúc, Việt Nam
}

Nhận ngày 10 tháng 2 năm 2017

Chỉnh sửa ngày 20 tháng 4 năm 2017; Chấp nhận đăng ngày 22 tháng 6 năm 2017

\begin{abstract}
Tóm tắt: Hiện nay ở Việt Nam, toàn ngành giáo dục đang thực hiện Nghị quyết số 29 NQ/TW, Hội nghị Trung ương 8 Khoá XI của Đảng về đổi mới căn bản và toàn diện đáp ứng yêu cầu của sự nghiệp công nghiệp hóa, hiện đại hóa. Bối cảnh đó đặt ra cho các cơ sở đào tạo GV trong cả nước hai nhiệm vụ lớn, có ảnh hưởng đến "vận mệnh" mỗi cơ sở đào tạo: Thứ nhất, làm thế nào để đào tạo được những thế hệ giáo viên $(\mathrm{GV})$ tương lai đủ năng lực giảng dạy chương trình giáo dục phổ mới? Thứ hai, làm thế nào để bồi dưỡng và đào tạo lại các $\mathrm{GV}$ đang trực tiếp giảng dạy ở phổ thông? Trên cơ sở khảo sát, nghiên cứu tổng quan về hai mô hình đào tạo $\mathrm{GV}$ (mô hình song song và mô hình kế tiếp-kết hợp) đang được áp dụng hiện nay, bài viết đưa ra những đề xuất cho việc phát triển chương trình đào tạo, bồi dưỡng $\mathrm{GV}$ đáp ứng yêu cầu đổi mới giáo dục phổ thông Việt Nam.
\end{abstract}

Tư khóa: Chương trình đào tạo; Bồi dưỡng giáo viên; Đổi mới giáo dục phổ thông.

\section{Tổng quan về chương trình đào tạo giáo viên ở Việt Nam hiện nay}

Ở Việt Nam hiện nay trình độ chuẩn được đào tạo của nhà giáo được quy định Điều 77 mục II Luật Giáo dục Việt Nam (2005) gồm: GV mầm non, GV tiểu học, GV trung học cơ sở; GV trung học phổ thông; GV hướng dẫn thực hành ở cơ sở dạy nghề; GV giảng dạy trung cấp; nhà giáo giảng dạy cao đẳng, đại học; nhà giáo giảng dạy chuyên đề, hướng dần luận văn thạc sĩ; hướng dẫn luận án tiễn sĩ [1]. Tương ứng với trình độ chuẩn được đào tạo là hệ thống các cơ sở đào tạo GV. Theo thống kê đến thời điểm năm 2012, cả nước có tổng số 133 cơ sở đào tạo, bồi dưỡng $\mathrm{GV}$ trong đó: 14

\footnotetext{
* Tác giả liên hệ. ĐT: 84-912153496.

Email: tuht@vnu.edu.vn

https://doi.org/10.25073/2588-1159/vnuer.4090
}

trường đại học sư phạm; 49 trường đại học có khoa/ngành sư phạm; 39 trường cao đẳng sư phạm; 24 trường cao đẳng có khoa/ngành sư phạm; 3 trường trung cấp sư phạm và 4 cơ sở đào tạo, bồi dưỡng cán bộ quản lí giáo dục [2].

Từ năm 2007, Bộ Giáo dục và Đào tạo (Bộ GD\&ĐT) đã ban hành Quy chế đào tạo đại học và cao đẳng hệ chính quy theo hệ thống tín chỉ. Theo đó, để hoàn thành chương trình đào tạo trình độ cử nhân đại học 4 năm, người học cần tích lũy từ 120 - 140 tín chỉ (tương đương với 180 - 210 đơn vị học trình) và Hiệu trưởng được quyền quy định cụ thể khối lượng kiến thức tối thiểu cho từng chương trình được triển khai đào tạo trong phạm vi trường mình [3]. Theo thống kê sơ bộ, nhìn chung ở các trường sư phạm tổng số tín chỉ này được cấu trúc như sau: khối kiến thức đại cương: $20 \%$; khối kiến thức giáo dục chuyên nghiệp: 69\%. Trong đó, 
cơ sở ngành: $43 \%$, chuyên ngành $26 \%$; thực tập: 5\%, khóa luận hoặc môn thay thế tốt nghiệp: $6 \%{ }^{1}$. Riêng với nội dung thực tập sư phạm sinh viên $(\mathrm{SV})$ sẽ có từ 10-12 tuần (có thể được chia thành 2 đợt) thực tập về kĩ năng, nghiệp vụ sư phạm theo môn học và công tác GV chủ nhiệm ở trường trung học phổ thông.

Công tác đào tạo $\mathrm{GV}$ chính quy đang được thực hiện theo hai mô hình là mô hình song song truyền thống (concurrent education model) và mô hình kế tiếp (consecutive education model). Trên thực tế, mỗi mô hình này đều có những ưu thế riêng trong việc đào tạo $\mathrm{GV}$. Việc công nhận và duy trì hai mô hình này sẽ tạo nên sự đa dạng trong phương thức đào tạo, hỗ trợ GV phát triển năng lực nghề nghiệp và chuyên môn sư phạm, tăng thêm sự lựa chọn cho người học muốn trở thành $\mathrm{GV}$ và theo kịp xu thế chung của giáo dục đại học trên thế giới [4].

Mô hình song song truyền thống được áp dụng phổ biến trong các trường/khoa chuyên đào tạo GV ở Việt Nam. Với mô hình này, quá trình đào tạo $\mathrm{GV}$ được thực hiện trong 4 năm (cử nhân đại học) hoặc 3 năm (cử nhân cao đẳng), trong đó việc đào tạo khoa học cơ bản và đào tạo sư phạm (nghiệp vụ) sẽ được tiến hành đồng thời. Mổ hình này có ưu thế là người học sớm xác định được được mục tiêu học tập là trở thành $G V$ và mục tiêu này liên tục được củng cố trong một môi trường sư phạm thuận lợi cho hình thành năng lực và nhân cách của các chuyên gia giáo dục. Nhưng nhược điểm của mô hình này là chậm chuyển đổi chương trình để thích ứng với thực tiễn. "Sư trì trệ trong $m o ̂$ hình đào tạo GV có nhiều nguyên nhân, nhung quan trọng là chúng ta chura thực sụ quan tâm làm rõ nền tảng tri thức của nghề dạy học" [5]. Nhận thức được điều này, trong 1- 2 năm trở lại đây, nhiều trường sư phạm thuộc mô hình

\footnotetext{
${ }^{1}$ Khảo sát chương trình đào tạo hiện hành của các trường Đại học: ĐHSP Hà Nội, ĐHSP Hà Nội 2, ĐH Giáo dục, ĐH Sư phạm Thái Nguyên, ĐH Sư phạm Thành phố Hồ Chí Minh (theo nguồn được công bố trên website chính thức của các trường Đại học và khảo sát thực tế).
}

này đã tích cực đẩy mạnh công tác xây dựng và phát triển chương trình nhằm khắc phục những hạn chế trước kia và tiến tới nâng cao chất lượng đào tạo.

Mô hình kế tiếp 3+1 tại trường Đại học Giáo dục (ĐHGD), Đại học Quốc gia Hà Nội, trong đó 3 năm đầu $\mathrm{SV}$ được đào tạo khối kiến thức khoa học cơ bản ở các trường thành viên, năm cuối về trường ĐHGD học kiến thức khoa học giáo dục và thực tập làm $\mathrm{GV}$ ở trường phổ thông. Mô hình này đã phát huy được tối đa sức mạnh của các đơn vị thành viên trong ĐHQGHN qua sự kết hợp khoa học cơ bản và khoa học giáo dục. Hiện nay, trường ĐHGD đang tiếp tục điều chỉnh và chuyển sang mô hình đào tạo kết hợp-kế tiếp $\mathbf{a}+\mathbf{b}$, theo đó trong giai đoạn a (với 135-137 tín chỉ) SV được đào tạo khối kiến thức khoa học cơ bản trong các lớp môn học cùng với $\mathrm{SV}$ các ngành tương ứng của trường ĐHKHTN và trường KHXH-NV. Sang giai đoạn b (với khoảng 28-57 tín chỉ, tuỳ theo chuyên ngành) SV được học khối kiến thức khoa học giáo dục và nghiệp vụ sư phạm, kiến tập-thực tập sư phạm (KT-TTSP) ở trường phổ thông ${ }^{2}$. Với chuẩn đầu ra được xây dựng bài bản, hệ thống năng lực cần hình thành cho $\mathrm{GV}$ được xác định rõ ràng, logic với chương trình đào tạo và cập nhật với đổi mới chương trình phổ thông, mô hình kế tiếp có những ưu thế nổi trội trong việc đào tạo $\mathrm{GV}$ có kiến thức chuyên môn vững vàng (vì những năm đầu được đào tạo như một cử nhân các chuyên ngành của khoa học cơ bản). Tuy nhiên, hạn chế của mô hình này là thời lượng phân bổ cho các học phần về khoa học giáo dục, KT-TTSP chưa nhiều (thực tập chỉ chiếm 3\% nội dung đào tạo $-4 / 135$ tín chỉ). Điều này sẽ dẫn đến thực tế kĩ năng sư phạm của người học chưa được rèn luyện nhiều, vì thế họ sẽ mất thêm thời gian để hoàn thiện kĩ năng sau khi ra

\footnotetext{
${ }^{2}$ Chương trình đào tạo Cử nhân Sư phạm của trường ĐHGD ban hành theo quyết định số 3606/QĐ-ĐHQGHN, ngày 30 tháng 9 năm 2015 .
} 
trường. Để khắc phục điều này, trường ĐHGD đã thực hiện việc đăng kí các lớp môn học với số lượng mỗi lớp khoảng 20-25 SV nhằm tăng cường thực hành, rèn luyện các kĩ năng nghề nghiệp cho các GV tương lai. Nội dung các môn học chuyên ngành cũng dành tỉ lệ cho các giờ thực hành nhiều hơn lí thuyết.

Nhìn chung, việc đào tạo GV ở Việt Nam trong những năm qua đã đạt được những thành tựu nhất định: sự mở rộng về quy mô, đa dạng trong mô hình đào tạo; cơ sở vật chất ngày càng được nâng cấp. Trong khoảng 5 năm trở lại đây chương trình đào tạo tại các trường sư phạm có nhiều điểm mới theo hướng phát huy năng lực người học. Những đóng góp của các trường sư phạm trong sự nghiệp giáo dục là không thể phủ nhận. Trong đó, quan trọng là việc đào tạo các thế hệ nhà giáo trong hơn 60 năm qua và $861.300 \mathrm{GV}$ đang trực tiếp giảng dạy trong một hệ thống giáo dục đầy đủ các cấp học ở mọi vùng, miền với nhiều loại hình trường lớp ${ }^{3}$. Bên cạnh đó, cũng góp phần đưa giáo dục và đào tạo ở Việt Nam đạt được những thành tựu đáng kể so với nhiều nước có thu nhập tính theo đầu người tương đương.

Tuy nhiên, việc đào tạo GV ở nước ta đang bộc lộ những hạn chế, bất cập so với yêu cầu thực tế, đặc biệt yêu cầu đổi mới căn bản, toàn diện giáo dục và đào tạo hiện nay.

Thư nhất, số luợng các co sở đào tạo GV hiện nay quá lớn so với nhu cầu của xã hội cũng như tỉ lệ chung của các quốc gia trên thế giới: Phần Lan chỉ có 11 trường đại học có chương trình đào tạo GV (bao gồm cả 5 cơ sở đào tạo GV dạy nghề) ${ }^{4}$, Úc là 22 cơ sở ơ $^{5}$ Anh là 73 trường ${ }^{6}$. Trong khi đó,

\footnotetext{
${ }^{3}$ Số liệu của Tổng cục thống kê (https://www.gso.gov.vn, truy cập ngày 12.10.2016).

4 Nguồn: The Center on International Education Benchmarking (http://www.ncee.org, truy cập ngày 11.10.2016).

5 Theo thống kê của Australian Education Network (http://www.australianuniversities.com.au/, truy cập ngày 11.10.2016).

${ }^{6}$ Bộ Giáo dục và Đào tạo, Nhũng vấn đề chung về phát triển chuoong trình đào tạo GV (Tài liệu tập huấn cán bộ,
}

theo báo cáo của UNESCO đến năm 2015, Việt Nam cần giảm khoảng $2 \% \mathrm{GV}$ vì sự suy giảm dân số trong độ tuổi đi học ${ }^{7}$. Điều này dẫn đến một thực tế là hàng vạn SV sư phạm ra trường không tìm được việc phù hợp với chuyên ngành đào tạo ${ }^{8}$. Đồng thời, nó cũng làm giảm sức hút của ngành sư phạm.

Thứ hai về chuoong trình đào tạo, nhìn chung cấu trúc chương trình đã có sự đổi mới theo hướng tăng khối kiến thức chuyên ngành nghiệp vụ và thực tập sư phạm so với chương trình trước kia. Tuy nhiên, khối kiến thức khoa học giáo dục mặc dù được đánh giá là rất quan trọng $(86.6 \% / 150$ người được khảo sát) nhưng thời gian phân bổ cho khối kiến thức này là chưa hợp lý và cần tăng thêm $(68 \%)$. Sự phối hợp giữa kiến thức khoa học cơ bản với kiến thức khoa học giáo dục còn chưa chặt chẽ (52\%). Các trường sư phạm vận dụng chương trình khung do Bộ quy định một cách máy móc và chương trình giữa các trường chưa có sự liên hệ với nhau $(52 \%)^{9}$, ngay cả trong 7 trường sư phạm trọng điểm. Bên cạnh đó, với tính chất đặc thù của các trường sư phạm là trường đào tạo nghề thì thời lượng cho nội dung thực hành nghề (thực tập) chưa thực sự tương xứng và ít hơn rất nhiều với các quốc gia có nền giáo dục sư phạm phát triển. Ví dụ ở Anh, thời gian thực tập là 24 tuần nếu chương trình đào tạo 3 năm; 32 tuần nếu đào tạo 4 năm; ở Pháp, Đức, Thổ Nhĩ Kì thời gian thực tập thường là 10 - 16 giờ/tuần ${ }^{10}$. Đây thực sự là những thách thức cho các cơ sở đào tạo $\mathrm{GV}$ trong việc xây dựng và

\footnotetext{
giảng viên các co sở đào tạo $G V$ phổ thông và phát triển chuong trình đào tạo), H.2015, tr. 37.

7 UNESCO, Teachers and Educational quality: Monitoring Global needs for 2015, UNESCO Institute for Statistics, Montreal, 2006, p. 80.

8 Theo Báo Điện tử Đài Tiếng nói Việt Nam (http://vov.vn/, truy cập ngày 12.10.2106)

${ }^{9}$ Bộ Giáo dục và Đào tạo, Sđd, tr.181.

10 Songül Kilimci, Teacher Training in Some EU Countries and Turkey: How similar are they?, Procedia Social and Behavioral Sciences 1, 2009, p. 1975-1980.
} 
phát triển chương trình đáp ứng yêu cầu đổi mới của giáo dục phổ thông hiện nay. Như vậy, có thể thấy điểm yếu trong chương trình đào tạo GV của Việt Nam hiện nay thể hiện sự hạn chế trong gắn kết đào tạo ở trường đại học với thực tiễn nghề nghiệp ở phổ thông.

\section{Thực trạng công tác tập huấn, bồi dưỡng giáo viên ở trường phổ thông}

Trong phạm vi bài viết này, khảo sát chưa được tiến hành trên diện rộng, mới chỉ tập trung vào $64 \mathrm{GV}$ môn Lịch sử tốt nghiệp cả 2 mô hình thuộc các trường: Đại học Sư phạm Hà Nội, Đại học Sư phạm Hà Nội 2, Đại học Đà Lạt, Đại học Tây Bắc, Đại học Giáo dục ĐHQG Hà Nội, Đại học Vinh, Đại học Sư phạm Thái Nguyên, Đại học Sư phạm Thành phố Hồ Chí Minh, Đại học Cần Thơ. Các GV này có kinh nghiệm giảng dạy thực tế từ 1 năm trở lên và hiện đang công tác tại các trường THPT thuộc Hà Nội, Hải Phòng, Hải Dương, Nam Định, Lào Cai, Bắc Giang, Vĩnh Phúc, Hà Giang, Phú Thọ, Bình Dương, Thành phố Hồ Chí Minh, Bình Thuận, Ninh Thuận. Hệ thống các trường THPT - cơ quan công tác của $\mathrm{GV}$ được khảo sát bao gồm: trường chuyên, trường công lập, trường tư thục, trường quốc tế, trung tâm giáo dục thường xuyên. Với môi trường dạy học đa dạng và phân bố ở nhiều tỉnh thành khác nhau trên khắp cả nước, những thông tin sẽ có giá trị trong việc phân tích thực trạng và đề xuất phát triển chương trình tập huấn, bồi dưỡng GV nói chung và $\mathrm{GV}$ môn Lịch sử nói riêng.

Trên thực tế, GV dù được đào tạo theo mô hình nào thì trong quá trình giảng dạy ở trường THPT đều phải tham gia các lớp tập huấn, bồi dưỡng của Bộ GD \& ĐT, các Sở GD \& ĐT các địa phương. Để có những đánh giá khách quan về công tác này, chúng tôi đã thiết kế phiếu khảo sát GV gồm 8 câu hỏi tập trung vào bốn nội dung sau: nội dung, phương pháp dạy học, kĩ thuật triển khai của giảng viên/chuyên gia trong các lớp tập huấn, bồi dưỡng $\mathrm{GV}$; mức độ thường xuyên và tính hiệu quả của các chương trình tập huấn và bồi dưỡng $\mathrm{GV}$; Thuận lợi và khó khăn của $\mathrm{GV}$ trong quá trình chuẩn bị cho việc dạy học theo định hướng của chương trình giáo dục phổ thông mới (theo hướng phát triển năng lực học sinh); Đề xuất của $G V$ về nội dung và $\mathrm{PP}$ tập huấn/kĩ thuật triển khai trong chương trình tập huấn, bồi dưỡng GV.

Kết quả khảo sát chung cho thấy chương trình bồi dưỡng $G V$ môn Lịch sử đã giúp $G V$ được cập nhật các phương pháp mới và vận dụng được một phần vào thực tế dạy học $(63.8 \%$ ý kiến $\mathrm{GV})$. Có $44.9 \% \mathrm{GV}$ cho rằng công tác tập huấn, bồi dưỡng chính là một trong những thuận lợi cho GV trong việc chuẩn bị dạy học theo định hướng của chương trình giáo dục phổ thông mới. Nội dung các khoá bồi dưỡng đã có sự thống nhất và bổ sung cho sự thiếu hụt trong chương trình đào tạo ở các trường sư phạm khi tập trung vào các phương pháp/kĩ thuật dạy học môn học (63.8 \% ý kiến). Về phương pháp, kĩ thuật triển khai của giảng viên/chuyên gia trong các lớp bồi dưỡng đã thể hiện sự tích cực, mang lại hiệu quả thực tế, với $27.5 \%$ ý kiến GV đánh giá phương pháp, kĩ thuật triển khai của giảng viên/chuyên gia chú trọng thực hành, khuyến khích sự tham gia của học viên và yêu cầu có sản phẩm sau đợt tập huấn.

Tuy vậy, kết quả khảo sát cũng cho thấy những yêu cầu thực tế mà chương trình bồi dưỡng GV cần tập trung giải quyết:

Truớc hết việc bồi dưỡng nâng cao năng lực GV phụ thuộc chủ yếu vào kế hoạch của các trường phổ thông hoặc theo lịch tập huấn chung của Bộ Giáo dục và Đào tạo (thường là 1 năm/lần) (72.5\% ý kiến), số lượng GV tự học, tự bồi dưỡng nâng cao trình độ còn rất hạn chế (18.8\% ý kiến).

Nội dung tập huấn, bồi duỡng vẫn thiếu những hướng dẫn rõ ràng để $\mathrm{GV}$ có thể triển khai trong chương trình mới (50.7\% ý kiến); nội dung các chuyên đề cập nhật kết quả nghiên cứu mới, chuyên đề mở rộng, chuyên sâu hơn nội dung kiến thức của môn học mà hiện chưa 
được chú trọng (ví dụ các chuyên đề về thành tựu kinh tế, văn hoá...).

Các giảng viên, chuyên gia bồi dưỡng mặc dù đã tổ chức các hoạt động cho học viên trao đổi thảo luận, nhưng $63.8 \% \mathrm{GV}$ cho rằng giảng viên/chuyên gia chủ yếu thuyết trình nội dung tập huấn.

Do đó, GV mong muốn tiếp tục được tham gia các lớp tập huấn, bồi dưỡng trong đó tập trung vào ba nội dung chính: thực hành các phương pháp và kĩ thuật dạy học phù hợp chương trình mới (59.4\% ý kiến); thực hành các hình thức/phương pháp và kĩ thuật kiểm tra đánh giá phù hợp chương trình mới (56.5\% ý kiến); cách thức cấu trúc các chủ đề chuyên sâu/ tích hợp/tự chọn (44.9\% ý kiến). Bên cạnh đó, $94.2 \% \mathrm{GV}$ mong muốn sẽ có sách GV hướng dẫn dạy học theo chương trình mới với cấu trúc tập trung vào các nội dung sau: hướng dẫn các hoạt động mở rộng phù hợp các phong cách học đa dạng, phù hợp năng lực của học sinh (73.9\% ý kiến); hướng dẫn các phương pháp/kĩ thuật dạy học phù hợp bài học/chủ đề (62.3\% ý kiến); Cung cấp thêm thông tin, các ý tưởng hoạt động giúp GV triển khai dạy học để phát triển kĩ năng tư duy và phương pháp học tập cho học sinh $(65.2 \%$ ý kiến); Cung cấp thêm các tài liệu hỗ trợ cho GV trong giảng dạy (50.7\% ý kiến).

\section{Một số đề xuất phát triển chương trình đào tạo, bồi dưỡng giáo viên đáp ứng yêu cầu đổi mới giáo dục phổ thông ở Việt Nam}

Xu hướng chung và cấp thiết hiện nay cho cả hai mô hình đào tạo GV hiện nay ở Việt Nam là cần đào tạo những $\mathrm{GV}$ dạy học chương trình theo hướng hình thành và phát triển năng lực cho HS. Do vậy, việc học tập kinh nghiệm từ chương trình đào tạo, bồi dưỡng $\mathrm{GV}$ của nước ngoài; việc đánh giá các kĩ năng nghề nghiệp của $\mathrm{GV}$ là rất cần thiết làm cơ sở điều chỉnh, cập nhật chương trình đào tạo và xây dựng chương trình tập huấn, tài liệu bồi dưỡng GV cũng được đặt ra cấp thiết.
3.1. Hoc tập kinh nghiệm nước ngoài, cập nhật, điều chỉnh chuoong trình đào tạo, bồi duỡng giáo viên

Chương trình đào tạo $\mathrm{GV}$ của các nước tiên tiến có những ưu thế riêng, phù hợp với đặc trưng của sự phát triển từng nước. Song, để vận dụng cho thực tiễn đổi mới ở Việt Nam có thể tập trung vào những điểm cơ bản như: Chương trình cần được thiết kế dựa theo chuẩn đầu ra làm cơ sở xác định thời lượng, nội dung khối kiến thức phù hợp đảm bảo cho $\mathrm{SV}$ ra trường đáp ứng được yêu cầu thực tiễn; Phương thức đào tạo cần chú trọng đến việc trải nghiệm thực tiễn giáo dục ở nhà trường phổ thông qua liên kết giữa các cơ sở đào tạo với các trường phổ thông thực hành [6]. Mô hình kế tiếp-kết hợp của trường ĐHGD đã và đang đi theo định hướng này. Theo định hướng chuẩn đầu $\mathrm{ra}$, chương trình đào tạo khối ngành sư phạm được điều chỉnh, cập nhật hàng năm đã thể hiện được sự gắn kết sản phẩm đầu ra với mô hình hoạt động nghề nghiệp đặc trưng của người $\mathrm{GV}$. Từng khối kiến thức được mô tả cụ thể những chuẩn cần đạt về kiến thức và năng lực chuyên môn. Đồng thời chương trình còn mô tả các kĩ năng chuyên môn (kĩ năng nghề nghiệp, kĩ năng tư duy và giải quyết vấn đề, kĩ năng nghiên cứu, khám phá kiến thức, kĩ năng đánh giá bối cảnh xã hội, tổ chức, kĩ năng vận dụng sáng tạo các kiến thức, kĩ năng vào thực tiễn nghề nghiệp); kĩ năng bổ trợ (kĩ năng cá nhân, làm việc theo nhóm, quản lý, lãnh đạo, hoạt động xã hội, giao tiếp và sử dụng ngoại ngữ, tin học) và các phẩm chất đạo đức. Việc kết hợp chặt chẽ với các trường phổ thông trong việc thực hành, rèn luyện các năng lực nghề nghiệp được thực hiện qua mô hình GV "vệ tinh" (mời các GV ở trường PT làm GV kiêm nhiệm, quản lý hướng dẫn $\mathrm{SV}$ trong các đợt KT-TTSP) được triển khai trong nhiều năm qua đã khẳng định được hiệu quả. Bên cạnh mô hình KT-TT tập trung (triển khai liên tục trong 8-10 tuần), hiện tại trường ĐHGD cũng đang tiếp tục thử nghiệm 
mô hình đưa SV KT-TT dài hạn (triển khai liên tục trong khoảng 6 tháng trong đó $\mathrm{SV}$ sắp xếp kế hoạch vừa học tập tại trường đại học, vừa tham gia thực tập làm $\mathrm{GV}$ ở trường $\mathrm{PT}$.

Đáp ứng yêu cầu của đổi mới GDPT, nhu cầu của $\mathrm{GV}$, chương trình đào tạo, tập huấn không chỉ cập nhật, điều chỉnh giúp các $\mathrm{GV}$ đáp ứng được chuẩn nghề nghiệp của quốc gia mà còn phải hướng đến chuẩn quốc tế, theo $\mathrm{xu}$ hướng dạy học của thế giới hiện nay. Chương trình đào tạo $\mathrm{GV}$ theo chuẩn quốc tế của $\mathrm{CIE}$ (University of Cambridge International Examination - Đại học Khảo thí Cambridge) tập trung vào phát triển các kĩ năng nghề nghiệp cho GV như: kĩ năng lập kế hoạch dạy học (chương trình học hoặc bài học) dựa trên cơ sở xác định nhu cầu, năng lực của $\mathrm{HS}$, xác định mục tiêu học tập; kĩ năng triển khai dạy học tích cực (hỗ trợ việc học tập tích cực của người học,); kĩ năng kiểm tra đánh giá kết quả học tập và kĩ năng đánh giá cải tiến việc dạy học. Các kĩ năng này giúp $\mathrm{GV}$ thực hiện hiệu quả hoạt động dạy học theo hướng phát triển năng lực HS, thực hiện một quy trình dạy học khoa học và chuyên nghiệp theo các bước: Chuẩn bị (Lập kế hoạch $\mathrm{DH}$ ), thực thi (căn cứ vào mục tiêu bài học/chuyên đề lựa chọn nội dung, hình thức tổ chức $\mathrm{DH}$, phương pháp/kĩ thuật $\mathrm{DH}$, hình thức/phương pháp kiểm tra đánh giá phù hợp, đánh giá vì sự thành công của người học ) và đánh giá cải tiến (lưu trữ hồ sơ, minh chứng, đánh giá thường xuyên phát triển chuyên môn và cải tiến việc $\mathrm{DH})^{11}$.

\section{2. Đánh giá các kĩ năng nghề nghiệp của giáo viên}

Cấu trúc năng lực nghề nghiệp của $\mathrm{GV}$ ở Việt Nam được xây dựng theo "Chuẩn nghề nghiệp GV trung học (gồm GV THCS và THPT)". Trong đó GV THPT cần phải có 5

\footnotetext{
$\overline{11}$ Tài liệu tập huấn: Chương trình đào tạo và cấp bằng, chứng chỉ quốc tế của Đại học khảo thí Cambridge cho GV và chuyên gia đào tạo, H.2007.
}

năng lực nghề nghiệp sau: Tìm hiểu đối tượng và môi trường giáo dục, Dạy học, Giáo dục, Hoạt động chính trị, xã hội, Phát triển nghề nghiệp. Trên cơ sở mô tả các năng lực trên, cần cụ thể hoá thành hệ thống các tiêu chí, tiêu chuẩn đánh giá sâu các kĩ năng của $\mathrm{GV}$. Kết quả đánh giá không chỉ cung cấp các thông tin tin cậy về thực trạng đạt được các năng lực nghề nghiệp của $G V$ so với các chuẩn đã ban hành mà còn đề xuất được những biện pháp kịp thời để cải tiến, cập nhật chương trình đào tạo, tập huấn GV đáp ứng yêu cầu của công cuộc đổi mới căn bản, toàn diện của giáo dục Việt Nam hiện nay. Việc đánh giá năng lực nghề nghiệp của GV là rất cần thiết. Song để kết quả đánh giá có thể làm cơ sở cho việc phát triển chương trình đào tạo, tập huấn $\mathrm{GV}$ hiệu quả, thực tế triển khai không được tiến hành một cách hình thức mà cần có các nghiên cứu sâu hơn để có thể xây dựng những bộ công cụ đánh giá cụ thể và khách quan hơn. Đánh giá không chỉ hướng tới việc cho điểm như hiện nay mà còn cần thu thập được các minh chứng cần thiết cho việc thể hiện khả năng đạt được.

Ví dụ, với kĩ năng dạy học-một trong các kĩ năng cơ bản của người $\mathrm{GV}$, dựa theo chuẩn nghề nghiệp và học tập từ chương trình đào tạo GV theo chuẩn quốc tế của CIE, có thể mô tả hệ thống kĩ năng dạy học mà GV cần có. Từ đó cụ thể hoá các tiêu chí và mô tả theo các mức đạt tương ứng với các minh chứng của các công việc, sản phẩm mà GV đã làm. Trong phạm vi đề tài nghiên cứu, chúng tôi xây dựng bộ phiếu đánh giá kĩ năng dạy học của GV gồm 2 phiếu: Phiếu khảo sát (dành cho $G V$ và tổ chuyên môn) và phiếu khảo sát ý kiến HS. Theo đó, việc đánh giá kĩ năng dạy học của $\mathrm{GV}$ được dựa trên 3 nguồn thông tin: tự đánh giá, đánh giá của đồng nghiệp, nhà quản lý chuyên môn và đánh giá của HS. Phiếu tự đánh giá của $G V$ (cũng như đánh giá của tổ chuyên môn) tập trung vào 5 kĩ năng: Nghiên cứu đối tượng dạy hoc, môi truờng dạy học; Lâp kế hoạch dạy học; Tổ chức triển khai dạy học; Kiểm tra, 
đánh giá kết quả họ tập của HS; Tư đánh giá cải tiến hoạt động dạy học, phát triển chuyên môn. Tương ứng với 5 kĩ năng đó là 15 tiêu chí và mức điểm phù hợp (từ 1 đến 4 ) và minh chứng kèm theo. Tổng hợp điểm GV tự đánh giá theo các mức đạt, tự đánh giá điểm mạnh, điểm yếu và đề xuất thêm ý kiến cho chương trình đào tạo $\mathrm{GV}$ của trường $\mathrm{DHGD}$ để đáp ứng được yêu cầu thực tiễn ở trường phổ thông. Phiếu khảo sát ý kiến HS cũng theo 5 kỹ năng và 15 tiêu chí song chỉ tập trung ý kiến HS vào việc xác nhận các tiêu chí và các minh chứng (Có hay Không), qua đó thu thập được thông tin làm cơ sở để đối chiếu về thực trạng kĩ năng dạy học của $\mathrm{GV}^{12}$.

\subsection{Xây dựng chuơng trình tập huấn, tài liệu bồi dướng giáo viên}

Căn cứ vào yêu cầu của công cuộc đổi mới căn bản và toàn diện giáo dục và đào tạo hiện nay, theo nhu cầu và mong muốn của $\mathrm{GV}$ qua khảo sát, nội dung chương trình tập huấn $\mathrm{GV}$ cần tập trung vào các vấn đề cơ bản sau:

- Hệ thống các chuyên đề bồi dưỡng kiến thức cho $\mathrm{GV}$ theo định hướng chương trình GDPT mới. Trong đó các chuyên đề không chỉ cập nhật các kết quả nghiên cứu mới mà còn tập trung vào các nội dung mở rộng, chuyên sâu trong môn học giúp các $\mathrm{GV}$ thuận lợi hơn trong việc lựa chọn, xây dựng các chủ đề bắt buộc/tự chọn, chủ đề cơ bản/nâng cao, xây dựng kế hoạch dạy học phù hợp điều kiện dạy học. Khi tập huấn các chuyên đề này, giảng viên/chuyên gia không chỉ tập trung vào giới thiệu kiến thức mà còn hướng dẫn $\mathrm{GV}$ cách thức cấu trúc các chủ đề, lựa chọn các kiến thức cơ bản hay nâng cao phù hợp năng lực HS.

\footnotetext{
${ }^{12}$ Hoàng Thanh Tú, Báo cáo tổng kết đề tài nghiên cứu "Đánh giá kĩ năng dạy học của GV (tốt nghiệp ngành Sư phạm Lịch sử Trường Đại học Giáo dục-ĐHQGHN) đáp ứng chuẩn nghề nghiệp GV THPT, Trường ĐHGD, 2014.
}

- Quy trình dạy học khoa học giúp GV thực hiện công việc dạy học chuyên nghiệp hơn, đáp ứng được yêu cầu của thực tiễn, phù hợp bối cảnh dạy học và tập trung vào phát triển năng lực HS. Trong thực tế, dù được đào tạo theo chương trình chung, sau khi ra trường, mức độ thành công của các GV là khác nhau, năng lực nghề nghiệp của các GV cũng phân hoá khác nhau. Qua quá trình công tác, phần lớn $\mathrm{GV}$ thực hiện công việc dạy học theo kinh nghiệm, thói quen hoặc vì yêu cầu của nhà quản lý trực tiếp chứ chưa thực sự vì nhu cầu tự đánh giá cải tiến hay vì HS. Điều này không chỉ làm hạn chế dần sự đổi mới, sáng tạo của mỗi $\mathrm{GV}$ mà còn là yếu tố trở ngại cho sự nghiệp đổi mới chung. Vì vậy, việc đào tạo lại qua tập huấn, bồi dưỡng có vai trò rất quan trọng giúp các $\mathrm{GV}$ từng bước hoàn thiện và phát triển năng lực chuyên môn của mình.

- Hệ thống bài tập thực hành tổng hợp các kĩ năng cũng như chuyên sâu từng kĩ năng giúp GV không chỉ đáp ứng chuẩn nghề nghiệp trong nước mà còn theo định hướng chuẩn quốc tế. Bài tập thực hành tổng hợp các kĩ năng yêu cầu GV vận dụng từ kĩ năng nghiên cứu đối tượng, môi trường dạy học đến lập kế hoạch dạy học. Với bài tập này, GV được thực hành kĩ năng lập kế hoạch dạy học môn học theo cách thức gắn kết hệ thống từ: xác định năng lực, nhu cầu của HS làm cơ sở xây dựng mục tiêu, làm lịch trình chi tiết, dự kiến nội dung, hình thức tổ chức $\mathrm{DH}, \mathrm{PPDH}$, kiểm tra đánh giá theo hướng phát triển năng lực HS và đánh giá cải tiến phát triển chuyên môn. Với hệ thống bài tập thực hành cùng những chỉ dẫn của giảng viên/chuyên gia, sau mỗi đợt tập huấn, GV không chỉ được "nghe" chỉ dẫn mà còn được "thực hành" làm ra các sản phẩm, ngoài ra còn thảo luận, trao đổi góp ý các sản phẩm, hoàn thiện và ứng dụng triển khai trong thực tiễn dạy học sau này.

Bên cạnh các tài liệu được biên soạn theo yêu cầu của chương trình tập huấn, cần có thêm các tài liệu hướng dẫn dạy học theo định hướng 
phát triển năng lực HS với các ví dụ minh hoạ (theo chương trình, SGK mới của môn học), sách $G V$ với các chỉ dẫn về tổ chức các hoạt động học tập đa dạng theo phong cách học, năng lực HS; các PP/KTDH theo mục tiêu bài học/chuyên đề; các tài liệu tham khảo hỗ trợ (trích dẫn rõ ràng từ các sách tham khảo hoặc đường dẫn đến các tài liệu trực tuyến). Về điểm này có thể tham khảo, học tập kinh nghiệm biên soạn sách hướng dẫn $\mathrm{GV}$ của nhiều nước có nền giáo dục phát triển trong đó có Úc-quốc gia hiện cũng thực hiện chương trình, SGK theo hướng phát triển năng lực HS. Các sách hướng dẫn giảng dạy hay sách $\mathrm{GV}$ cho chương trình phổ thông hiện hành của Việt Nam được biên soạn rất phong phú song chưa gắn kết chặt chẽ theo chương trình, còn được biên soạn rời rạc (theo từng lĩnh vực riêng, ví dụ: hướng dẫn sử dụng kênh hình SGK, tư liệu tham khảo, câu hỏi, bài tập...), các chỉ dẫn còn chung chung hoặc cách thức sử dụng còn chưa đa dạng khiến GV khó khăn trong việc tham khảo, lựa chọn cách thức phù hợp cho đối tượng HS của mình.

Sự thành công của công cuộc đổi mới giáo dục hiện nay phụ thuộc vào nhân tố chính là các GV đang trực tiếp giảng dạy ở hệ thống các trường phổ thông. Vì vậy, chương trình đào tạo của các trường đại học-cơ sở đào tạo $\mathrm{GV}$ cần luôn cập nhật những yêu cầu mới, xác định được chuẩn đầu ra rõ ràng, học tập và vận dụng linh hoạt kinh nghiệm của quốc tế để có thể đào tạo được đội ngũ $G V$ có năng lực giáo dục và giảng dạy thế hệ trẻ thành những công dân toàn cầu. Chương trình tập huấn, bồi dưỡng cho các GV đang công tác cũng rất cần thiết và cần sự thống nhất từ nội dung, cách thức tập huấn cũng như sự phối hợp, hỗ trợ và thống nhất trong đánh giá của các cấp quản lý. Bên cạnh đó khả năng tự học, tự nghiên cứu, tự bồi dưỡng thường xuyên của mỗi GV sẽ giúp họ có khả năng tự hoàn hoàn thiện, đáp ứng được yêu cầu của thực tiễn dạy học luôn cần sự đổi mới, sáng tạo hiện nay. Đặc biệt cũng cần tạo được động lực phát triển nghề nghiệp cho $\mathrm{GV}$ và lấy cộng đồng giáo viên mỗi nhà trường làm đơn vị cơ bản để bồi dưỡng phát triển nghề nghiệp chuyên môn.

\section{Lời cảm ơn}

Nghiên cứu này được tài trợ từ nguồn kinh phí Khoa học công nghệ của Trường ĐHSP Hà Nội 2 cho đề tài mã số: C.2016-18-11.

\section{References}

[1] Luật Giáo dục (2005), (Cơ sở dữ liệu Quốc gia về Văn bản pháp luật: http://www.moj.gov.vn; truy cập ngày 11.10.2016).

[2] Phạm Xuân Hậu, Nguyễn Thị Hằng, Đổi mới phương pháp đào tạo $\mathrm{GV}$ : xu hướng và những giải pháp cần vận dụng ở trường Đại học Sư phạm TP. Hồ Chí Minh, Tạp chí KH ĐHSP TPHCM, số 5/2013, tr. 10 - 11.

[3] Quyết định số 43/2007/QĐ-BGDĐT của Bộ Giáo dục và Đào tạo: Ban hành Quy chế đào tạo đại học và cao đẳng hệ chính quy theo hệ thống tín chỉ (http://vanban.chinhphu.vn - Cổng thông tin điện tử Chính phủ nước Cộng hòa xã hội chủ nghĩa Việt Nam, truy cập ngày 22/8/2016.

[4] Xem thêm: Živilè Sederevičiūtè-Pačiauskienè1 Dr.paed.; Brigita Vainorytė2, The Concurrent and Consecutive Models of Initial Teacher Training: Problematics and Tendencies, RURAL ENVIRONMENT. EDUCATION. PERSONALITY ISSN 2255-808X, p. 347- 354.

[5] Nguyễn Văn Ninh, Mô hình đào tạo giáo viên của nước Cộng hòa Pháp và khả năng vận dụng vào Việt Nam, Kỷ yếu Hội thảo Quốc gia về dạy học Lịch sử ở trường phồ thông Việt Nam, NXB Giáo dục, H. 2012, tr. 741.

[6] Đinh Quang Báo (chủ biên), Chương trình đào tạo giáo viên đáp ứng yêu cầu đổi mới giáo dục phổ thông, NXB Đại học Sư phạm, H. 2016, tr.41-42. 


\title{
Developing Teacher Training Programs to Meet the Requirements of General Education Innovation in Vietnam
}

\author{
Hoang Thanh $\mathrm{Tu}^{1}$, Ninh Thi Hanh ${ }^{2}$ \\ ${ }^{I}$ VNU University of Education, 144 Xuan Thuy, Cau Giay, Hanoi, Vietnam \\ ${ }^{2}$ Faculty of History, Hanoi Pedagogical University, \\ 32 Nguyen Van Linh, Xuan Hoa, Phuc Yen, Vinh Phuc, Vietnam
}

\begin{abstract}
The implementation of the Communist Party Resolution No.29-NQ/TW on radical and comprehensive innovation in education, serving industrialisation and modernisation has posed two vital tasks to the country's teacher training institutions: 1) How to train future generations of teachers capable of teaching the new general education curriculum? and 2) How to foster and retrain the current teachers?

Based on the survey results and research overview of the two teacher training models (concurrent education model and consecutive education model), this article proposes some measures to develop the training teacher programs meeting the requirements of the general education innovation in Vietnam.
\end{abstract}

Keywords: Training program, teacher training program, general education innovation. 